Sharif University of Technology
Scientia Iranica
Transactions A: Civil Engineering
SCIENTIA
IRAN I CA

\title{
Ultimate compressive strength of deteriorated steel web plate with pitting and uniform corrosion wastage
}

\author{
Y. Sharifi ${ }^{\mathrm{a}, \mathrm{b}, *}$, S. Tohidi ${ }^{\mathrm{a}}$ and J.K. Paik ${ }^{\mathrm{b}}$ \\ a. Department of Civil Engineering, Vali-e-Asr University of Rafsanjan, Rafsanjan, Iran. \\ b. Department of Naval Architecture and Ocean Engineering, The Korea Ship and Offshore Research Institute (The Lloyd's Register \\ Foundation Research Center of Excellence) at Pusan National University, Busan 46241, Korea.
}

Received 31 October 2014; received in revised form 23 April 2015; accepted 10 August 2015

\section{KEYWORDS \\ Pitting corrosion; \\ Steel structures; \\ Ultimate load- \\ carrying capacity; \\ Nonlinear finite \\ element analyses.}

\begin{abstract}
Steel structural members are likely to be exposed to corrosive environments and thus, corrosion is one of the dominant life-limiting factors of steel structures. Extensive studies on the effects of pitting and uniform corrosion on the strength performance of steel structural members under a wide variety of loading conditions have been undertaken to assess the relationship between pitting corrosion intensity and residual strength. The aim of this study is to investigate the ultimate compressive strength characteristics of steel web plate elements with pit and uniform corrosion wastage. A series of ABAQUS nonlinear elastic-plastic large deformation finite element analyses are carried out on Ishaped section steel girder models with varying pitting corrosion intensities. Artificial pitting of different intensities is considered on the web plates and a uniform loading is applied vertically on the upper flange section. The ultimate load-carrying capacity of the deteriorated models with different levels of uniform thickness loss is also studied. The results are applied to the assessment of the ultimate compressive strength of web plates with different pitting corrosion intensities and a uniform loss thickness by developing design formulae that represent the average loss thickness versus the ultimate load-carrying capacity.

(C) 2016 Sharif University of Technology. All rights reserved.
\end{abstract}

\section{Introduction}

Sea water creates an attacking corrosive environment, because it is an active electrolyte and contains corrosive salts. Marine environment is a sea water environment, and this means that corrosion in marine structures, which are generally fabricated by various grades of steel, is often very severe, not only under sustained immersed condition as in ballast tanks, but also from general exposure to atmospheric conditions [1-14].

*. Corresponding author. Tel.: +98391 3202404;

Fax: +983913202202

E-mail addresses: yasser_sharifi@yahoo.com and

y.sharifi@vru.ac.ir (Y. Sharifi); jeompaik@pusan.ac.kr

(J.K. Paik)
Corrosion damage can reduce the structural loadcarrying capacity or cause leaks in oil or watertight boundaries, the latter possibly leading to undesirable pollution, cargo mixing, or gas accumulation in enclosed spaces [1]. Improper maintenance of ship structures may lead to disastrous casualties in rough seas and heavy weather. It is thus important to assess the residual strength of ageing ship structures, properly - whether they have corrosion or other types of defects - to inform inspection and maintenance programme of a vessel.

The evaluation of the residual strength of members with pitting corrosion is considered to be more difficult than the same evaluation of members with uniform corrosion [1-13]. Over the past few decades, there have been significant developments in computer 
hardware and Finite Element Analysis (FEA) software. The FEA method has now become the most common, powerful, and flexible tool in rational structural analysis, and makes it possible to predict the strength of complex structures more accurately than the classical theoretical methods. Although the finite element method can in principle be used to predict buckling and post-buckling strength, it still requires substantial computational time and cost. This means that empirical formulae are still necessary to assess structural integrity during initial design, inspection, and maintenance for effective on-site decisions [15$18]$.

This study investigates both general (uniform) and pitting corrosion. It is assumed that the thickness of the entire plate is uniformly reduced by general corrosion, but pit corrosion reduces the plate thickness in a localised region only. A large number of nonlinear FEAs are carried out on a beam damaged web plate with pitting corrosion. The results of these analyses are used to derive new empirical formulae to predict the ultimate strength and strength reduction of beam web plates with pitting corrosion under axial compression.

\section{Idealisation of corrosion damage}

General or uniform corrosion uniformly reduces the thickness of structural members whereas localised corrosion (e.g., pitting or grooving) causes degradation in local regions. Sometimes fatigue cracks may arise from localised corrosion.

The corrosion damage of steel structures is influenced by many factors, including the corrosion protection system and various operational parameters. In general, the corrosion protection systems used in ships or offshore platforms are coatings (paint) and anodes. The operational parameters include maintenance, repair, percentage of time in ballast, frequency of tank cleaning, temperature profiles, use of heating coils, humidity conditions, water and sludge accumulation, microbial contamination, and inert gas composition. To date, basic work to understand the effects of these many factors and their interactions is lacking for marine structures, although mathematical models for predicting the time-dependent corrosion wastage of ship structures have been developed [6-10].

Although the distribution of pit corrosion on plate is widely scattered, the shape of the corrosion is typically a circular cone, and the ratio of the diameter to the depth of the cone is in the range of 1 to 8 [3-5]. In this study, two types of corrosion damage idealisation are considered: general and pit corrosion.

To assess the scale of breakdown due to pit corrosion, a parameter denoting the degree of pit corrosion intensity, or DOP, is often used, which is defined as the percentage of the corroded surface area to the original plate surface area, namely [7]:

$$
\mathrm{DOP}=\frac{1}{a b} \sum_{i=1}^{n} A_{p i} \times 100(\%)
$$

where $n$ is the number of pits, $A_{p i}$ is the surface area of the $i$ th pit, $a$ is the plate length, and $b$ is the plate breadth.

Based on the analysis performed in [19], the ultimate strength loss due to the pitting corrosion damage in a plate model would just rely on the total corroded volume loss and the influence resulted from some other factors such as the pits distribution status, the pits shape, and the pits depth can be ignored. Thus, it can be seen from Eq. (1) and Ref. [19] that to assess the scale of breakdown due to pit corrosion, DOP may be expressed as:

$$
\mathrm{DOP}=\frac{1}{a b t} \sum_{i=1}^{n} V_{p i} \times 100(\%),
$$

where $n$ is the number of pits, $V_{p i}$ is the volume of the $i$ th pit, $a$ is plate length, $b$ is plate breadth, and $t$ is plate thickness.

\section{Modelling of beam sections with pitting corrosion}

Hull structural members are subjected to a corrosive environment that thins the plates of the structural members. As corrosion is one of the dominant factors that decrease the life of ships and offshore structures, it is very important to understand the effect of corrosion wastage not only on the overall strength, but also on the local strength, to ensure the safety of hull structures. The load-carrying capacity of these types of structures must be accurately evaluated.

The ultimate strength reduction characteristics of a beam web plate with pit corrosion under a compressive load are demonstrated by ABAQUS [20]. The strength of the pitted plates is determined by nonlinear FEA with changing geometrical features of the pits, which allows the effect of pitting corrosion on the ultimate compressive strength of the plates to be identified. An elasto-plastic analysis is conducted to simulate the effect of corrosion pits on the ultimate compressive strength behaviour.

\subsection{Basic geometric properties of pits}

The shape of the corrosion pits was observed [3] on the hold frames in a 12-year-old bulk carrier, a 20-year-old bulk carrier, a 14-year-old bulk carrier, and the bottom shells in a 22-year-old single hull tanker. It was found that the shape of the corrosion pit on surface of the hold frames in the bulk carriers is a circular cone, and that of the corrosion pit on surface of the bottom shell in the 
tanker is a part of a sphere. The ratio of the diameter to the depth is approximately constant, that is between 10:1 and 8:1 for the surface of the hold frames in the bulk carrier, and between 4:1 and 6:1 for the bottom shells in the tanker. The average diameters of the pit on the surface of two hold frames in the 14-year-old bulk carrier are 25 and $29 \mathrm{~mm}$.

As mentioned, based on the analysis performed in [19], the ultimate strength loss due to the pitting corrosion damage in a plate model would just rely on the total corroded volume loss, and influence resulted from some other factors such as the pits distribution status, the pits shape, and the pits depth can be ignored. Thus, in this paper, in order to assess the ultimate compressive strength of deteriorated steel web plate with pitting corrosion wastage, it is assumed that both sides of the web plate will corrode in a localised manner and the real corrosion pits on surfaces of hull structural plates, which generally appear as conical-shaped and/or semi-spherical-shaped [3], are assumed to be cylindrical shaped with the same distribution on plate surface, the same corroded volume loss, and the same diameter as those of the corresponding pits. It is also assumed that the pitting corrosion is uniformly distributed, but affects the strength of the plates differently, depending on the degrees of pitting intensity. Finally, it is assumed that the pit diameter to depth ratio is 8 [3-5], and the distance between the centres of adjacent pits is constant.

\subsection{Loading and boundary conditions}

Loading and boundary conditions of the steel beam are the same as those in [3]. The boundary conditions of the beam are shown in Figure 1. The bottom and upper flanges were fixed. The uniformly distributed loads are simulated with pressure in the form of uniform loading applied at the upper flanges of the beam, as shown in Figure 1.

\subsection{Mesh and material properties}

ABAQUS has several element types to simulate the buckling behaviour of beams. Among them, the fournode linear shell elements with reduced integration (S4R) were selected as they had the capability to simulate the complex buckling behaviour of thin steel beams, had six degrees of freedom per node, and provided accurate solutions to most applications. The beam was modelled as three plates representing the two flanges and the web. In order to determine the proper size of meshes, several trial models are examined and the results are compared with Nakai et al. [3]. The elements were $\mathrm{S} 4 \mathrm{R}$ with a $6 \mathrm{~mm}$ edge length. Element widths and element lengths equal to or less than $6 \mathrm{~mm}$ were selected as the suitable mesh sizes. Figure 2 shows FE mesh of a pitting corroded plate. As can be seen, in order to simulate the pit properly, very fine mesh sizes are used inside the pit.

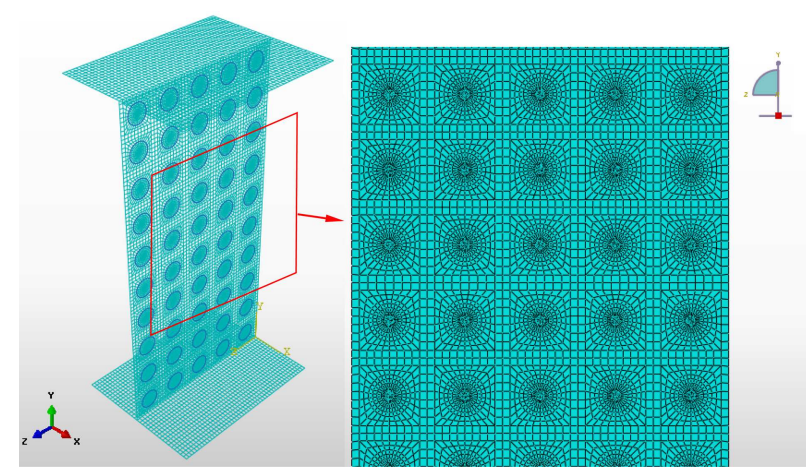

Figure 2. Finite element model of a pit in the corroded plate.

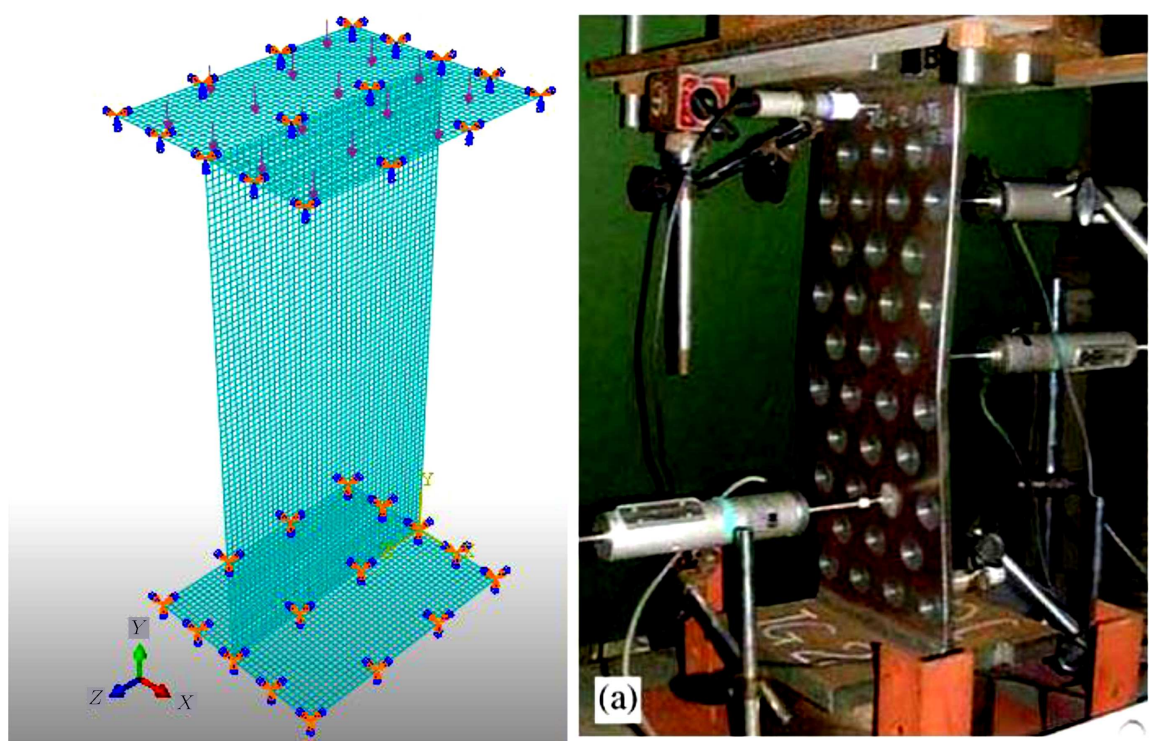

Figure 1. Model and boundary condition of a beam web plate. 


\subsection{Applied material properties}

The yield and inelastic flow of a metal at relatively low temperatures, where loading is relatively monotonic and creep effects are not important, can typically be described with the classical metal plasticity models. In ABAQUS, these models use standard Mises or Hill yield surfaces with an associated plastic flow. Perfect plasticity and isotropic hardening definitions are both available in the classical metal plasticity models. Common applications include crash analyses, metal forming, and general collapse studies (ABAQUS 2005). The ABAQUS metal plasticity model was applied in all the analyses. In this study, material behaviour for plate was modelled as a bilinear elasticplastic manner. A typical value for the modulus of elasticity $(E=205,800 \mathrm{MPa})$, Poisson's ratio of 0.3 , and values of yield stress for the web and flange plates of $397 \mathrm{MPa}$ are considered in this study. Several studies [21,22] have shown that the material properties of corroded steel can change. However, as mentioned, because we investigate the load-carrying capacity ratio of corroded specimens, changes in material properties do not affect the results and thus, the effect of corrosion on the material properties is not taken into account.

\subsection{Modelling of initial imperfection}

The buckling modes could be obtained by performing eigenvalue buckling analysis [20]. The first buckling mode is used in the eigenvalue analysis. Since buckling modes predicted by ABAQUS eigenvalue analysis [20] are generalised to 1.0, they are factored by a magnitude of $t_{w} / 30$, where $t_{w}$ is depth of the web plate.

\subsection{Nonlinear analysis}

ABAQUS has the ability to consider both geometric and material nonlinearities in a given model. The FEM analysis investigated in this study accounts for both geometrical and material nonlinearities. The load was applied in increments as static point load using the RIKS method available in the ABAQUS library. A full Newton-Raphson procedure along with an arc length control iterative is used in conjunction with an automatic incrimination strategy to solve the nonlinear equations [20]. The sign of the initial load increment follows the sign of the determinant of the tangent stiffness matrix. A convergence criterion based on the maximum norm of incremental displacements is adopted. In the incremental-iterative process, each load step consists of the application of an increment of the external loads and subsequent iterations to restore equilibrium.

\section{Validation of the modelling technique}

To validate the FEA, the analysed beams had crosssectional dimensions and material property identical to specimens J000, JE56, and JE34 in Nakai et al. [3]. The material of the web plates and flanges in steel beam structures is normally mild steel with a yield strength, $\sigma_{y}$, of $397 \mathrm{MPa}$ and an ultimate strength, $\sigma_{u}$, of $684 \mathrm{MPa}$. The Young's modulus and Poisson's ratio are $E=205800 \mathrm{MPa}$ and $\nu=0.3$, respectively. The geometrical model and load direction used in the FEA are the same as those used by Nakai et al. [3]. The load-vertical deflection and load-lateral deflection from Nakai et al. [3] and the current results are shown in Figures 3-6, where the curves in both cases present a consistent tendency and the ultimate strength values of beams match excellently.

The curves show a consistent tendency and the ultimate compressive strength values of the beams match excellently. This comparison validates the current results with other published results to provide confidence that the FEA simulation can accurately predict the decreased ultimate compressive strength of beams subjected to pitting corrosion. According to previous studies by Nakai et al. [3], the effect of welding residual stress is negligible and it has no effect on the results of assessments of the compressive strength of web plates. Moreover, the primary concern of this analysis is the ultimate strength reduction due to pit

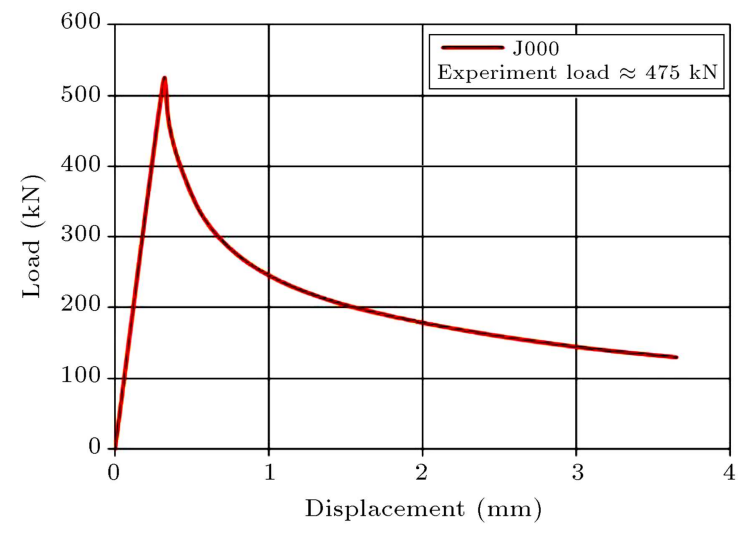

(a)

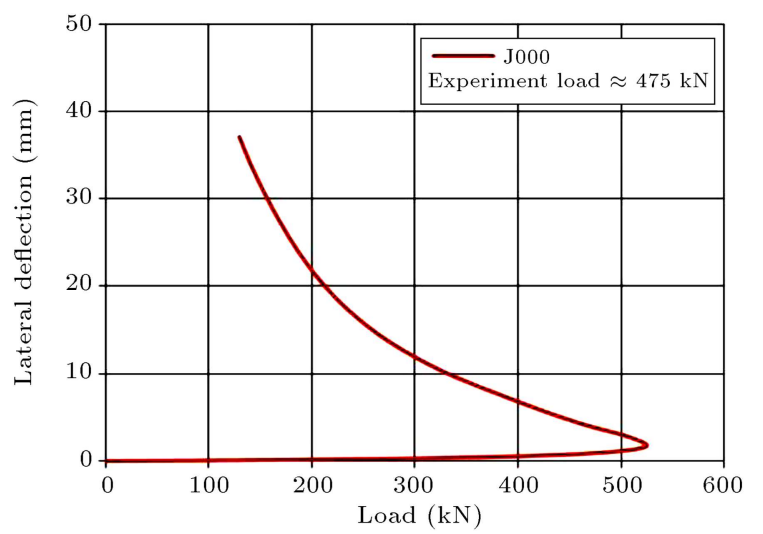

(b)

Figure 3. (a) Load-axial shortening. (b) Lateral deflection curves of J000 under a compressive load. 


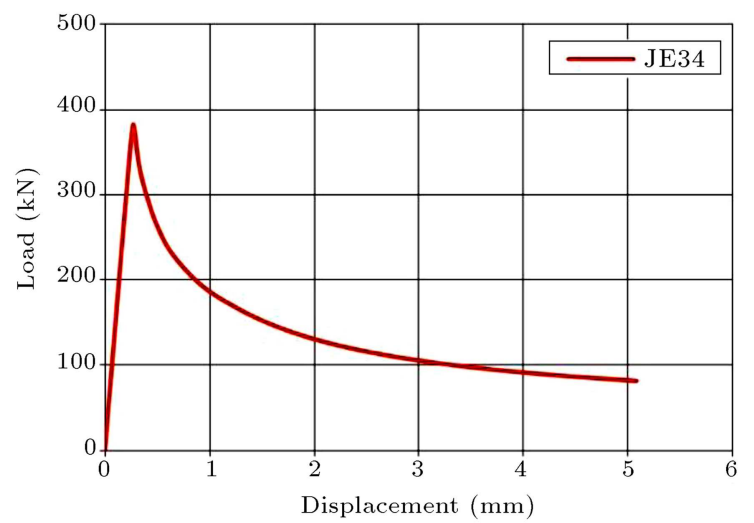

(a)

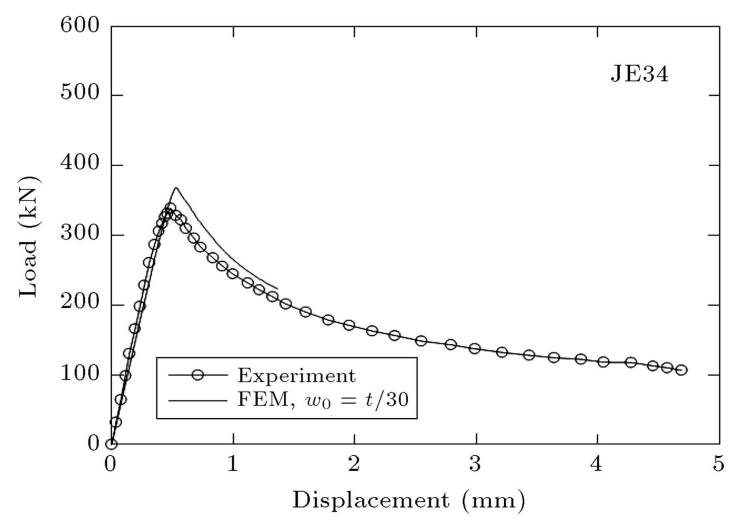

(b)

Figure 4. Load-axial shortening curves of JE34 under a compressive load: (a) From [3]; and (b) results of this study.

corrosion, or the ultimate strength ratio of a corroded plate to a perfect (un-corroded) plate. The effect of welding residual stress is thus neglected.

\section{Non-linear FEA and discussion}

\subsection{Effect of pitting corrosion on the ultimate strength}

In this section, the effect of corrosion pits distributed on both sides of the plate on the ultimate capacity of beam plates with a corroded web is investigated. Figure 7 shows a typical steel web plate between flanges in an Ibeam structure subjected to compressive loading. The web plate and flange length, breadth, and thickness denotations are also shown in Figure 7.

The geometry of the plate is shown in Table 1. A uniform distribution of pits on both sides of the web plate is assumed. The real shape of the corrosion pits is cylindrical with a pit diameter to depth ratio in the range of 4-10 [3-5] and thus, a real shape with a ratio of 8 is used to create various models with different DOPs. The pit corrosion characteristics are shown in Table 1. As Table 1 demonstrates, the range of DOP is between $0-41.8667 \%$. The geometric and material properties of the plate are as follow:

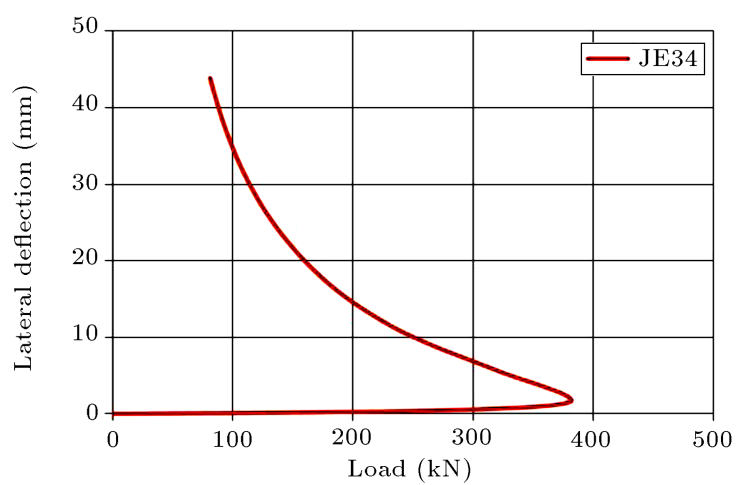

(a)

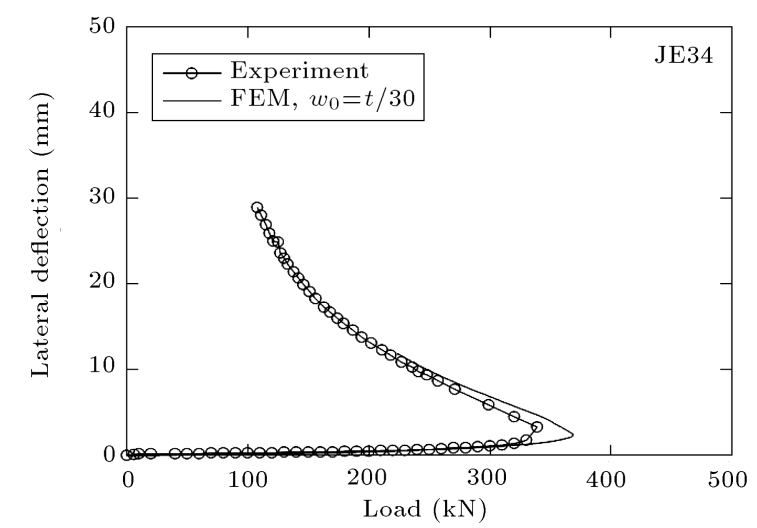

(b)

Figure 5. Load-lateral deflection curves of JE34 under a compressive load: (a) From [3]; and (b) results of this study.

- Plate breadth $(l)=250,150,250 \mathrm{~mm}$;

- Plate height $\left(h_{w}\right)=500,450,250 \mathrm{~mm}$;

- Plate thickness $(t)=12,16,20 \mathrm{~mm}$;

- Flange breadth $\left(b_{f}\right)=200,100 \mathrm{~mm}$;

- Flange thickness $\left(t_{f}\right)=25,15 \mathrm{~mm}$;

- Shape of pit corrosion = cylindrical;

- Elastic modulus $(E)=205.8 \mathrm{GPa}$;

- Poisson's ratio $(\nu)=0.3$;

- Material yield stress $\left(\sigma_{y}\right)=397 \mathrm{MPa}$.

The load-carrying capacity of specimens in the ultimate state are also summarised in Table 1 for each DOP. As expected, the capacity decreases as the DOP increases.

Figure 8 shows the compressive load curves versus maximum lateral deflections curves for G2-1 group beams; when varying different levels of pit corrosion intensity, it is obvious that the ultimate load and deformation behaviours are strongly affected by pit corrosion intensities.

The von Mises stress distribution and the yield point distribution of web plate girder with pitting corrosion damage and under axial compressive loads 


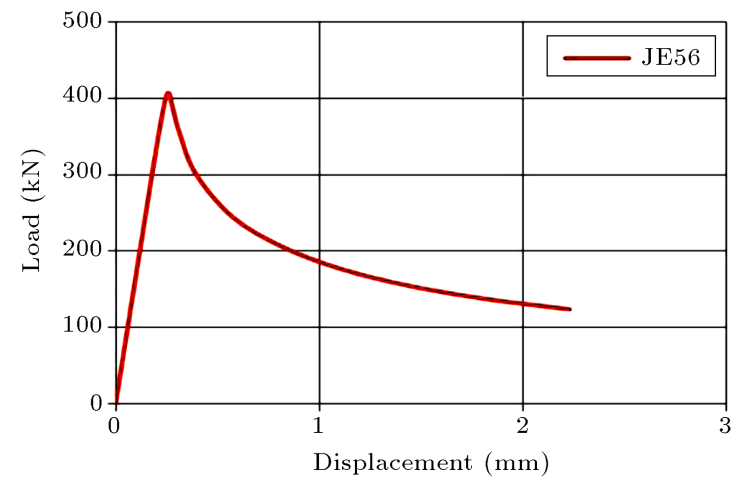

(a)

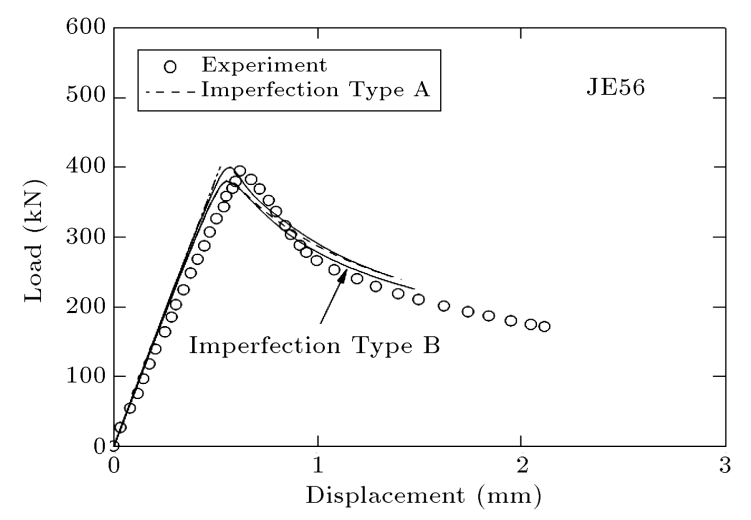

(b)

Figure 6. Load-axial shortening curves of JE56 under a compressive load: (a) From [3]; and (b) results of this study.

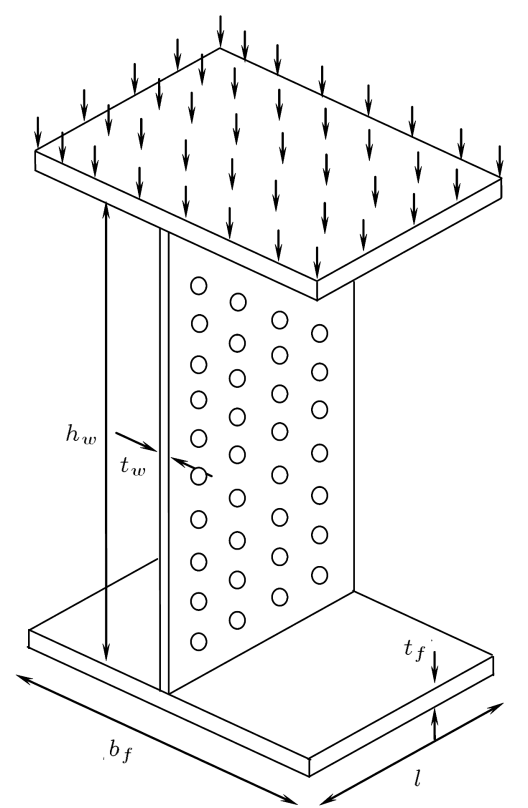

Figure 7. Typical model of a beam web plate.

immediately after the ultimate strength are shown in Figures 9 and 10, respectively. It is indicated that both maximum stresses and yielding in the web plate with larger pit corrosion intensity are smaller than those in the intact plate. This means that the web

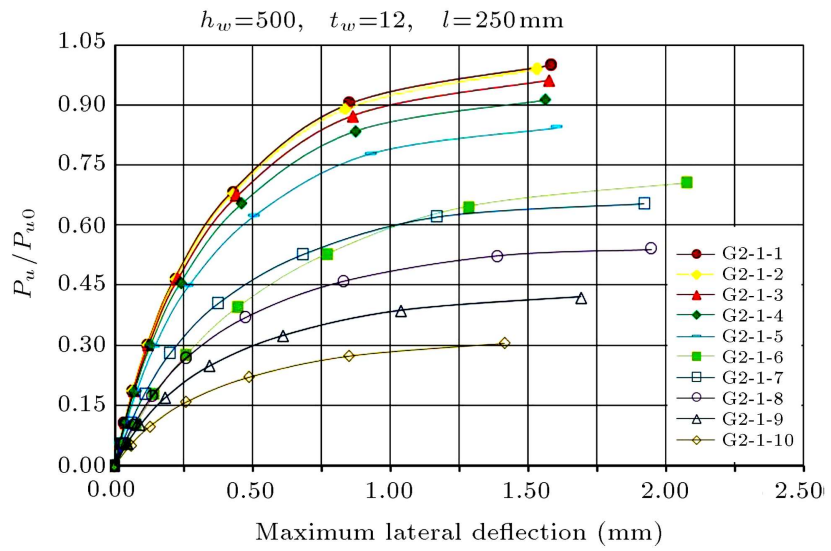

Figure 8. Load-maximum lateral deflection curves for specimens with different pitting corrosion intensities $\left(P_{u}\right.$ and $P_{u o}$ are the ultimate compressive strengths of the pitted and intact plates, respectively).

plate slenderness increases significantly as the DOP increases. Moreover, it can be seen from the figures that the mid-spans of the web plates are collapsed in FE analysis.

Figures 11 and 12 show $\left(P_{u} / P_{u 0}\right)$ ratios depending on the web corrosion damage condition. In these figures, the residual ultimate strength is drawn against various DOPs and different $\left(h_{w} / l\right)$ ratios. It can be found from Figures 11 and 12 that the $\left(h_{w} / l\right)$ ratio does not have a significant effect on the relative ultimate load of a pitted web plate girder. The residual ultimate strength of the pitted web plate is also related to the $t_{w}$ shown in Figures 11-16. The obvious conclusion is that the web plate thickness does not have a significant effect on the residual ultimate strength of corroded plate beams. However, the important conclusion from Figures 11-16 is that the ultimate strength reduction of the plates under axial compression loads with respect to the corroded volume loss is not affected by the web plate dimension; in fact, the influence of web plate slenderness is not important.

\subsection{Effect of uniform corrosion on the ultimate strength}

In the present study, the buckling behaviour of steel web plate beams was also analysed and the influence of web thickness loss on the ultimate strength was investigated using the FE program ABAQUS. For this purpose, three different sections with equal web thickness, but with web plate aspect ratio $\left(h_{w} / l\right)$ varying between 1 and 3 , were analysed. The web thickness loss $\left(t_{e} / t_{w}\right)$ ratio was selected for each cross section. The web thickness loss $\left(t_{e} / t_{w}\right)$ ratio of the selected web plate ranges from $1 / 12$ to $1 / 2$. This resulted in a series of 18 different models of steel web plate beams analyses. The geometric characteristics of web plate with uniform thickness loss and load-carrying capacitates are shown in Table 2. 
Table 1. Artificial pitting in structural models and FEA results for the ultimate strength of the models.

\begin{tabular}{|c|c|c|c|c|c|c|c|c|c|c|c|}
\hline Model & $h_{w}$ & $l$ & $t_{w}$ & $h_{w} / l$ & $h_{p}$ & $d_{p}$ & $h_{p} / t_{w}$ & $d_{p} / h_{p}^{*}$ & $\begin{array}{c}\text { Number } \\
\text { of } \\
\text { pits }\end{array}$ & DOP\% & $\boldsymbol{P}_{u} / \boldsymbol{P}_{u 0}$ \\
\hline G1-1-1 & 450 & 150 & 12 & 3 & 0.0 & 0 & 0.0000 & & 0 & 0.0000 & 1.0000 \\
\hline G1-1-2 & 450 & 150 & 12 & 3 & 1.0 & 8 & 0.0833 & 8 & 54 & 0.3349 & 0.9928 \\
\hline G1-1-3 & 450 & 150 & 12 & 3 & 1.5 & 12 & 0.1250 & 8 & 54 & 1.1304 & 0.9727 \\
\hline G1-1-4 & 450 & 150 & 12 & 3 & 2.0 & 16 & 0.1667 & 8 & 54 & 2.6795 & 0.9346 \\
\hline G1-1-5 & 450 & 150 & 12 & 3 & 2.5 & 20 & 0.2083 & 8 & 54 & 5.2333 & 0.8740 \\
\hline G1-1-6 & 450 & 150 & 12 & 3 & 3.0 & 24 & 0.2500 & 8 & 54 & 9.0432 & 0.7962 \\
\hline G1-1-7 & 450 & 150 & 12 & 3 & 3.5 & 28 & 0.2917 & 8 & 54 & 14.3603 & 0.7041 \\
\hline G1-1-8 & 450 & 150 & 12 & 3 & 4.0 & 32 & 0.3333 & 8 & 54 & 21.4357 & 0.5968 \\
\hline G1-1-9 & 450 & 150 & 12 & 3 & 4.5 & 36 & 0.3750 & 8 & 54 & 30.5208 & 0.4755 \\
\hline G1-1-10 & 450 & 150 & 12 & 3 & 5.0 & 40 & 0.4167 & 8 & 54 & 41.8667 & 0.3426 \\
\hline G1-2-1 & 450 & 150 & 16 & 3 & 0.0 & 0 & 0.0000 & & 0 & 0.0000 & 1.0000 \\
\hline G1-2-2 & 450 & 150 & 16 & 3 & 1.0 & 8 & 0.0625 & 8 & 54 & 0.2512 & 0.9963 \\
\hline G1-2-3 & 450 & 150 & 16 & 3 & 1.5 & 12 & 0.0938 & 8 & 54 & 0.8478 & 0.9855 \\
\hline G1-2-4 & 450 & 150 & 16 & 3 & 2.0 & 16 & 0.1250 & 8 & 54 & 2.0096 & 0.9627 \\
\hline G1-2-5 & 450 & 150 & 16 & 3 & 2.5 & 20 & 0.1563 & 8 & 54 & 3.9250 & 0.9224 \\
\hline G1-2-6 & 450 & 150 & 16 & 3 & 3.0 & 24 & 0.1875 & 8 & 54 & 6.7824 & 0.8678 \\
\hline G1-2-7 & 450 & 150 & 16 & 3 & 3.5 & 28 & 0.2188 & 8 & 54 & 10.7702 & 0.7984 \\
\hline G1-2-8 & 450 & 150 & 16 & 3 & 4.0 & 32 & 0.2500 & 8 & 54 & 16.0768 & 0.7168 \\
\hline G1-2-9 & 450 & 150 & 16 & 3 & 4.5 & 36 & 0.2813 & 8 & 54 & 22.8906 & 0.6226 \\
\hline G1-2-10 & 450 & 150 & 16 & 3 & 5.0 & 40 & 0.3125 & 8 & 54 & 31.4000 & 0.5172 \\
\hline G1-3-1 & 450 & 150 & 20 & 3 & 0.0 & 0 & 0.0000 & & 0 & 0.0000 & 1.0000 \\
\hline G1-3-2 & 450 & 150 & 20 & 3 & 1.0 & 8 & 0.0500 & 8 & 54 & 0.2010 & 0.9975 \\
\hline G1-3-3 & 450 & 150 & 20 & 3 & 1.5 & 12 & 0.0750 & 8 & 54 & 0.6782 & 0.9897 \\
\hline G1-3-4 & 450 & 150 & 20 & 3 & 2.0 & 16 & 0.1000 & 8 & 54 & 1.6077 & 0.9752 \\
\hline G1-3-5 & 450 & 150 & 20 & 3 & 2.5 & 20 & 0.1250 & 8 & 54 & 3.1400 & 0.9474 \\
\hline G1-3-6 & 450 & 150 & 20 & 3 & 3.0 & 24 & 0.1500 & 8 & 54 & 5.4259 & 0.9067 \\
\hline G1-3-7 & 450 & 150 & 20 & 3 & 3.5 & 28 & 0.1750 & 8 & 54 & 8.6162 & 0.8535 \\
\hline G1-3-8 & 450 & 150 & 20 & 3 & 4.0 & 32 & 0.2000 & 8 & 54 & 12.8614 & 0.7898 \\
\hline G1-3-9 & 450 & 150 & 20 & 3 & 4.5 & 36 & 0.2250 & 8 & 54 & 18.3125 & 0.7143 \\
\hline G1-3-10 & 450 & 150 & 20 & 3 & 5.0 & 40 & 0.2500 & 8 & 54 & 25.1200 & 0.6289 \\
\hline G 2-1-1 & 500 & 250 & 12 & 2 & 0.0 & 0 & 0.0000 & & 0 & 0.0000 & 1.0000 \\
\hline G 2-1-2 & 500 & 250 & 12 & 2 & 1.0 & 8 & 0.0833 & 8 & 100 & 0.3349 & 0.9895 \\
\hline G 2-1-3 & 500 & 250 & 12 & 2 & 1.5 & 12 & 0.1250 & 8 & 100 & 1.1304 & 0.9618 \\
\hline G 2-1-4 & 500 & 250 & 12 & 2 & 2.0 & 16 & 0.1667 & 8 & 100 & 2.6795 & 0.9128 \\
\hline G2-1-5 & 500 & 250 & 12 & 2 & 2.5 & 20 & 0.2083 & 8 & 100 & 5.2333 & 0.8412 \\
\hline G2-1-6 & 500 & 250 & 12 & 2 & 3.0 & 24 & 0.2500 & 8 & 100 & 9.0432 & 0.7052 \\
\hline G2-1-7 & 500 & 250 & 12 & 2 & 3.5 & 28 & 0.2917 & 8 & 100 & 14.3603 & 0.6524 \\
\hline G2-1-8 & 500 & 250 & 12 & 2 & 4.0 & 32 & 0.3333 & 8 & 100 & 21.4357 & 0.5392 \\
\hline G2-1-9 & 500 & 250 & 12 & 2 & 4.5 & 36 & 0.3750 & 8 & 100 & 30.5208 & 0.4206 \\
\hline G2-1-10 & 500 & 250 & 12 & 2 & 5.0 & 40 & 0.4167 & 8 & 100 & 41.8667 & 0.3044 \\
\hline G 2-2-1 & 500 & 250 & 16 & 2 & 0.0 & 0 & 0.0000 & & 0 & 0.0000 & 1.0000 \\
\hline G 2-2-2 & 500 & 250 & 16 & 2 & 1.0 & 8 & 0.0625 & 8 & 100 & 0.2512 & 0.9940 \\
\hline G 2-2-3 & 500 & 250 & 16 & 2 & 1.5 & 12 & 0.0938 & 8 & 100 & 0.8478 & 0.9767 \\
\hline G 2-2-4 & 500 & 250 & 16 & 2 & 2.0 & 16 & 0.1250 & 8 & 100 & 2.0096 & 0.9442 \\
\hline G2-2-5 & 500 & 250 & 16 & 2 & 2.5 & 20 & 0.1563 & 8 & 100 & 3.9250 & 0.8957 \\
\hline
\end{tabular}


Table 1. Artificial pitting in structural models and FEA results for the ultimate strength of the models (continued).

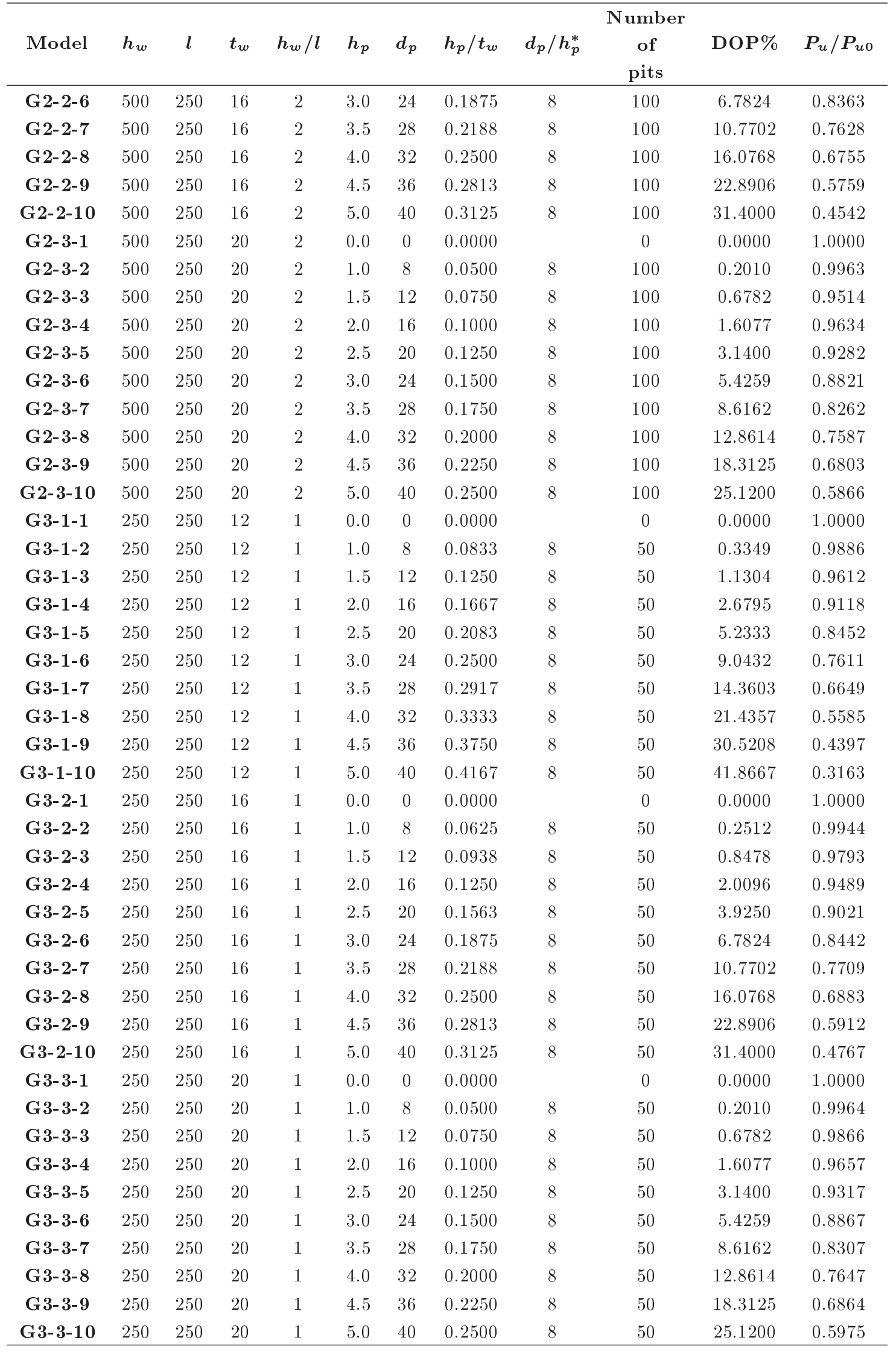

$* d_{p}=$ Pit diameter; $h_{p}=$ Pit depth 

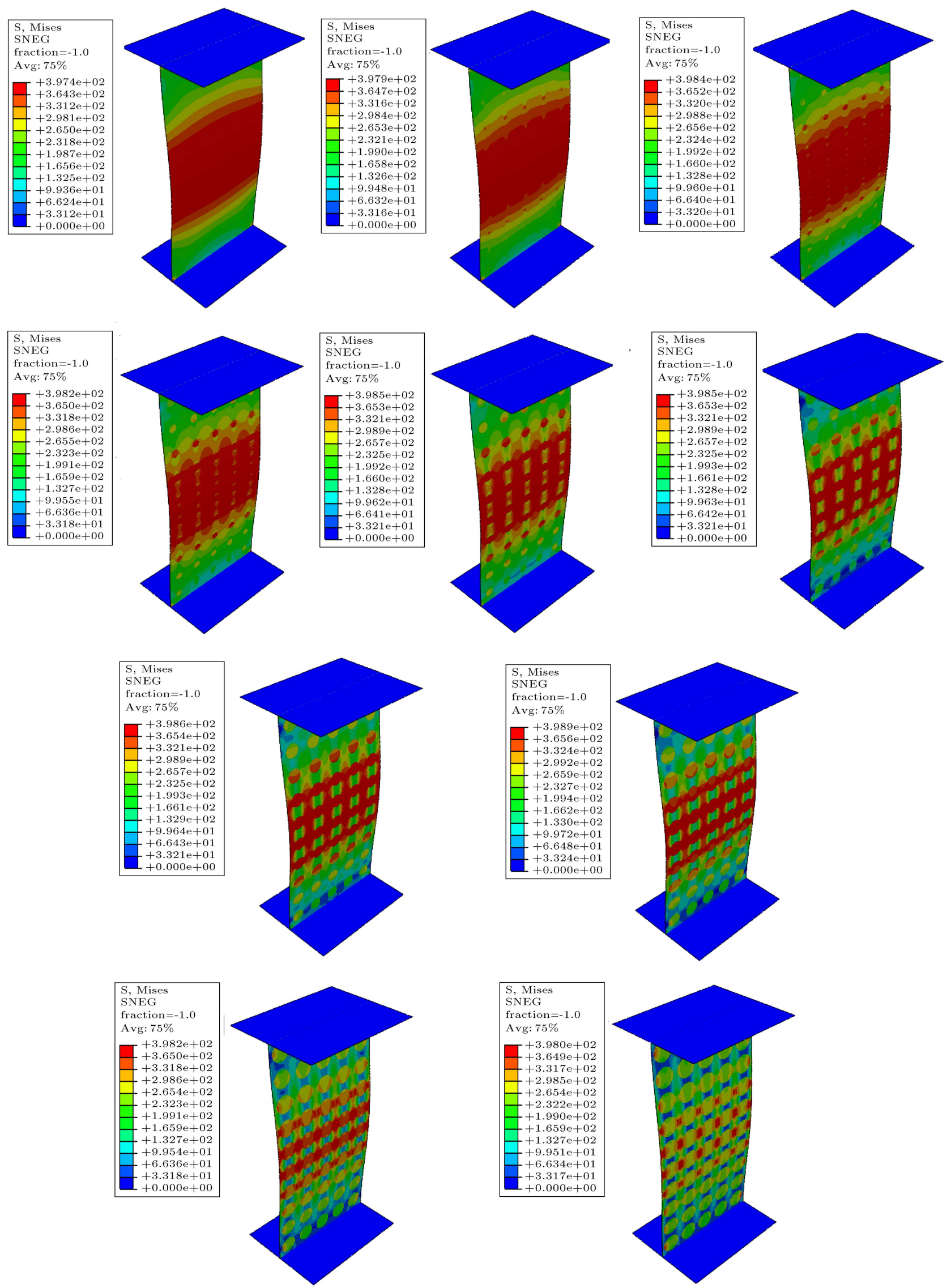

Figure 9. The von Mises stress distribution of web plate girder models at the ultimate state. 

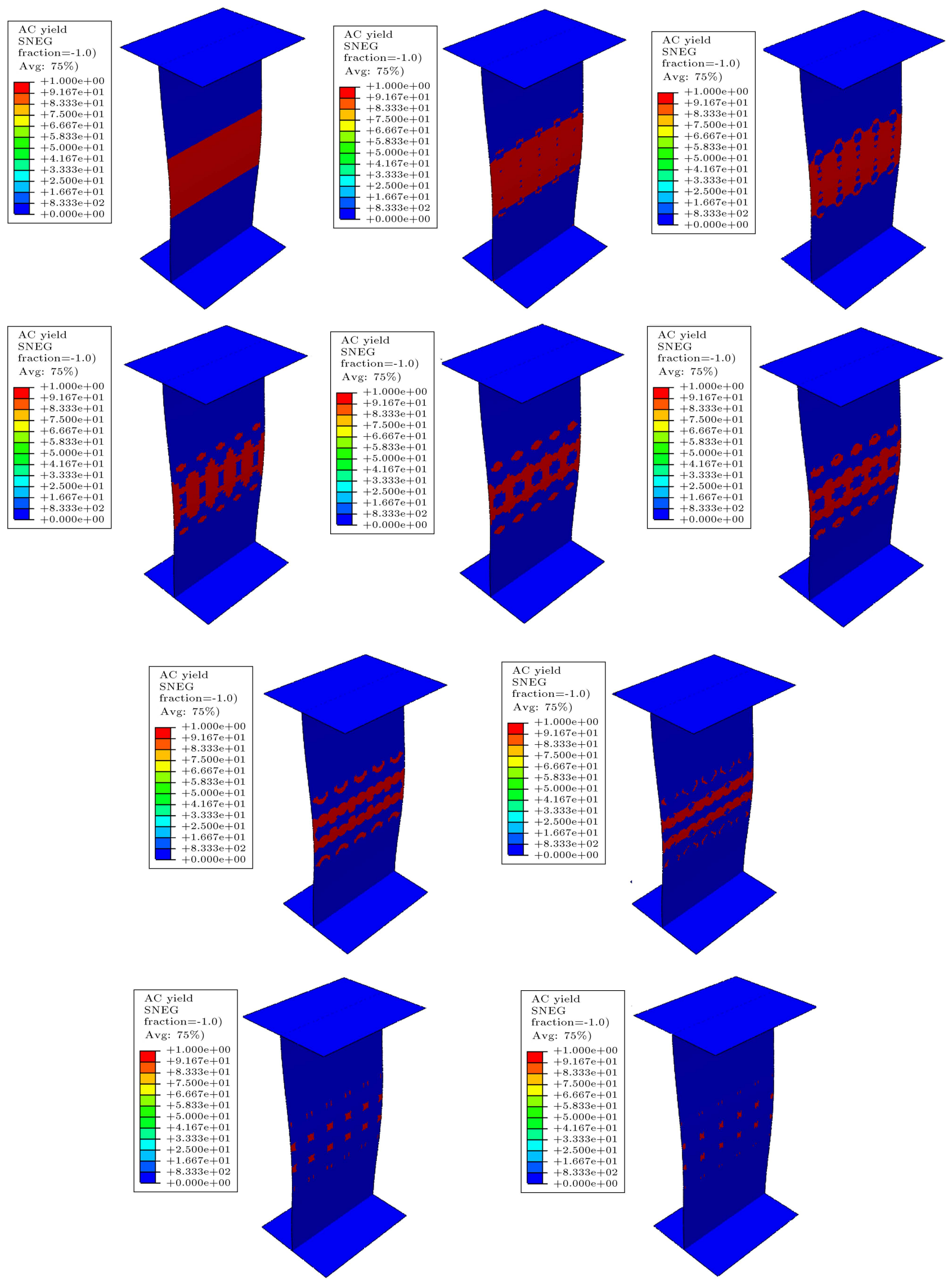

Figure 10. The actively yielding distribution of web plate girder models at the ultimate state. 


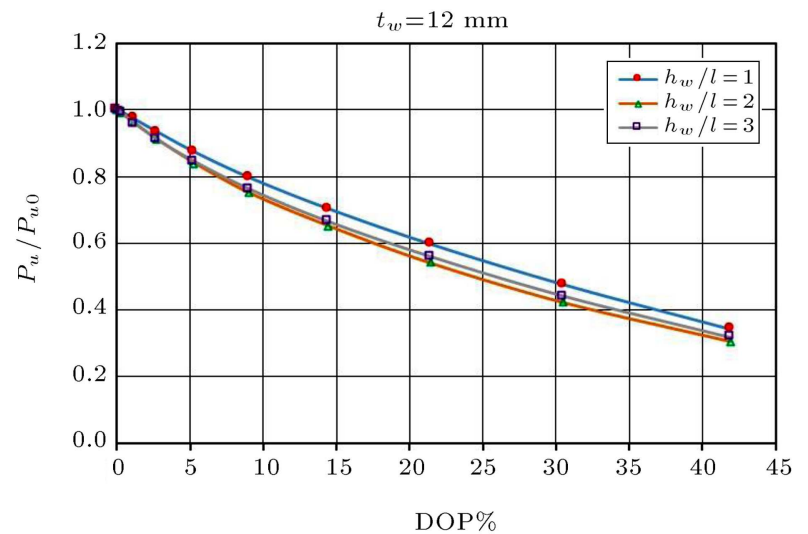

Figure 11. Ultimate strength versus DOP for a steel web plate with pit corrosion under axial compression, varying $h_{w} / l$ for $t_{w}=12 \mathrm{~mm}$.

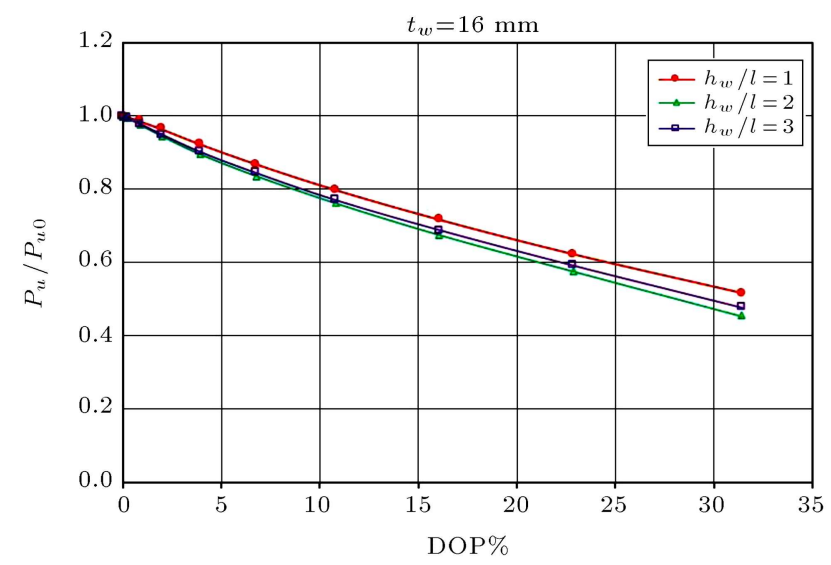

Figure 12. Ultimate strength versus DOP for a steel web plate with pit corrosion under axial compression, varying $h_{w} / l$ for $t_{w}=16 \mathrm{~mm}$.

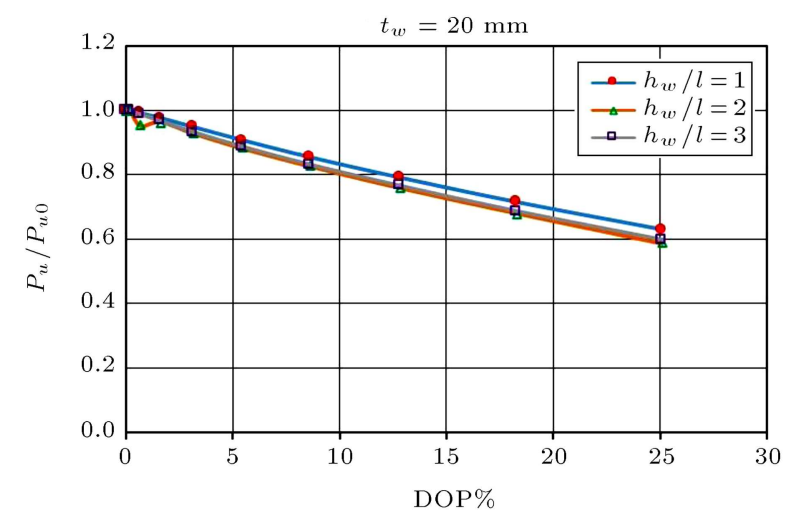

Figure 13. Ultimate strength versus DOP for a steel web plate with pit corrosion under axial compression, varying $h_{w} / l$ for $t_{w}=20 \mathrm{~mm}$.

\section{Ultimate compressive strength formulae}

As mentioned before, evaluating the residual strength of members with pitting corrosion, which results in surface unevenness, is difficult. The foregoing analyses used a rather complicated method of modelling pitted

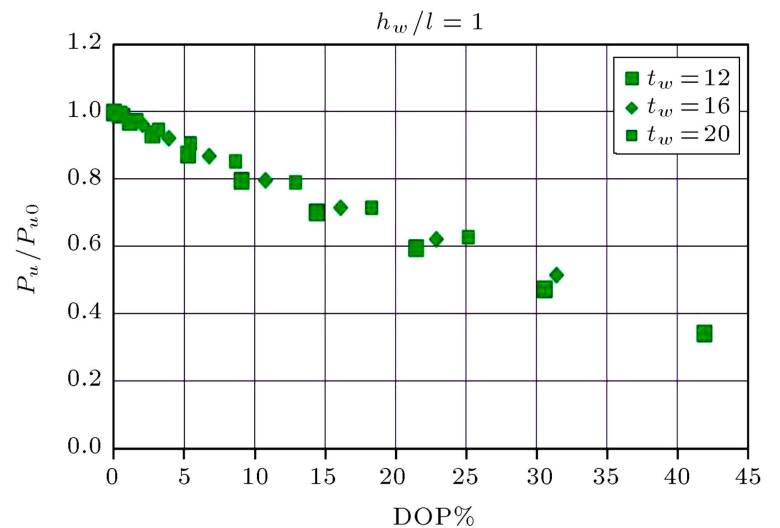

Figure 14. Ultimate strength versus DOP for a steel web plate with pit corrosion under axial compression, varying $t_{w}$ for $h_{w} / l=1$.

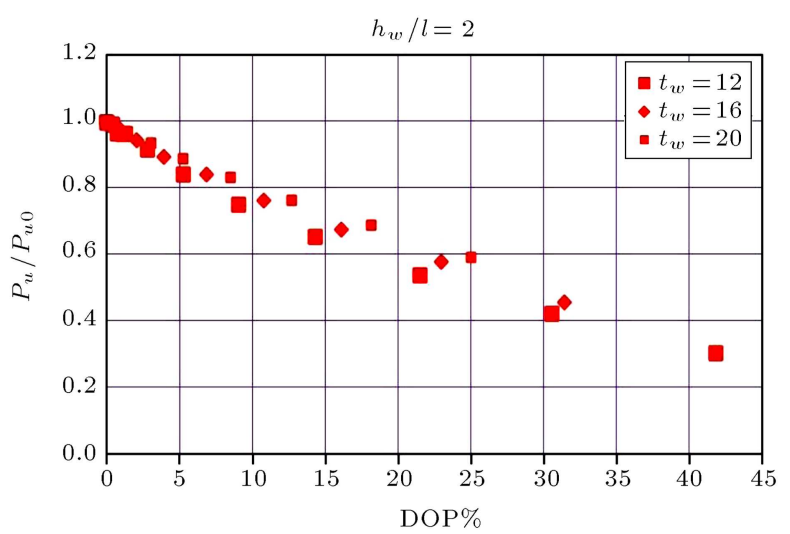

Figure 15. Ultimate strength versus DOP for a steel web plate with pit corrosion under axial compression, varying $t_{w}$ for $h_{w} / l=2$.

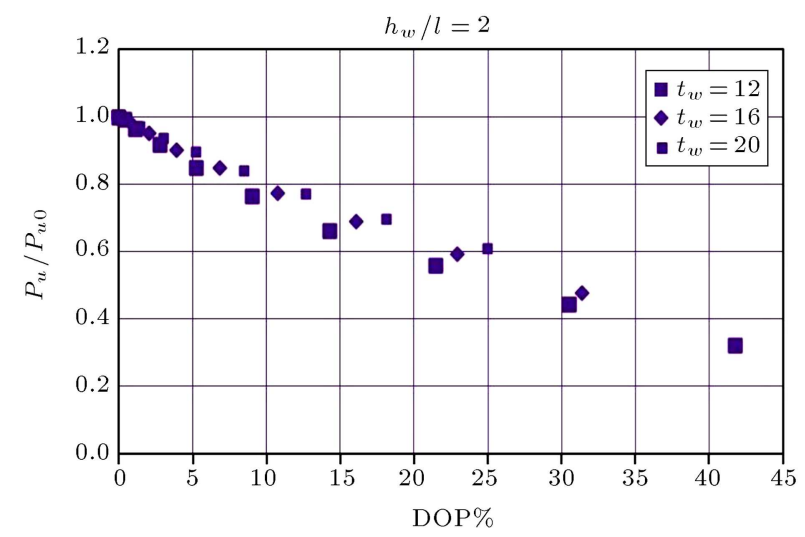

Figure 16. Ultimate strength versus DOP for a steel web plate with pit corrosion under axial compression, varying $t_{w}$ for $h_{w} / l=3$.

members. A simpler method is thus needed for practical purposes. In practical application, it is desirable to predict a pitted corrosion surface from a surface that is corroded uniformly. There are several formulations for estimating the ultimate strength of a shape-plate member as a function of thickness. Here, we attempt 
Table 2. Uniform thickness loss in structural models and FEA results for the ultimate strength of the models.

\begin{tabular}{cccccccc}
\hline Model & $\boldsymbol{t}_{\boldsymbol{w}}$ & $\boldsymbol{h}_{\boldsymbol{w}}$ & $\boldsymbol{l}$ & $\boldsymbol{t}_{\boldsymbol{e}}$ & $\boldsymbol{t}_{\boldsymbol{e}} / \boldsymbol{t}_{\boldsymbol{w}}$ & $\boldsymbol{a} / \boldsymbol{b}$ & $\boldsymbol{p}_{\boldsymbol{u}} / \boldsymbol{p}_{\boldsymbol{u} \mathbf{0}}$ \\
\hline M1-0 & 12 & 250 & 250 & 0 & 0.00 & 1 & 1.00 \\
M1-1 & 12 & 250 & 250 & 1 & 0.08 & 1 & 0.82 \\
M1-2 & 12 & 250 & 250 & 2 & 0.17 & 1 & 0.65 \\
M1-3 & 12 & 250 & 250 & 3 & 0.25 & 1 & 0.49 \\
M1-4 & 12 & 250 & 250 & 4 & 0.33 & 1 & 0.35 \\
M1-5 & 12 & 250 & 250 & 5 & 0.42 & 1 & 0.24 \\
M1-6 & 12 & 250 & 250 & 6 & 0.50 & 1 & 0.16 \\
M2-0 & 12 & 500 & 250 & 0 & 0.00 & 2 & 1.00 \\
M2-1 & 12 & 500 & 250 & 1 & 0.08 & 2 & 0.90 \\
M2-2 & 12 & 500 & 250 & 2 & 0.17 & 2 & 0.81 \\
M2-3 & 12 & 500 & 250 & 3 & 0.25 & 2 & 0.71 \\
M2-4 & 12 & 500 & 250 & 4 & 0.33 & 2 & 0.60 \\
M2-5 & 12 & 500 & 250 & 5 & 0.42 & 2 & 0.49 \\
M2-6 & 12 & 500 & 250 & 6 & 0.50 & 2 & 0.37 \\
M3-0 & 12 & 450 & 150 & 0 & 0.00 & 3 & 1.00 \\
M3-1 & 12 & 450 & 150 & 1 & 0.08 & 3 & 0.84 \\
M3-2 & 12 & 450 & 150 & 2 & 0.17 & 3 & 0.69 \\
M3-3 & 12 & 450 & 150 & 3 & 0.25 & 3 & 0.53 \\
M3-4 & 12 & 450 & 150 & 4 & 0.33 & 3 & 0.39 \\
M3-5 & 12 & 450 & 150 & 5 & 0.42 & 3 & 0.27 \\
M3-6 & 12 & 450 & 150 & 6 & 0.50 & 3 & 0.17 \\
\hline
\end{tabular}

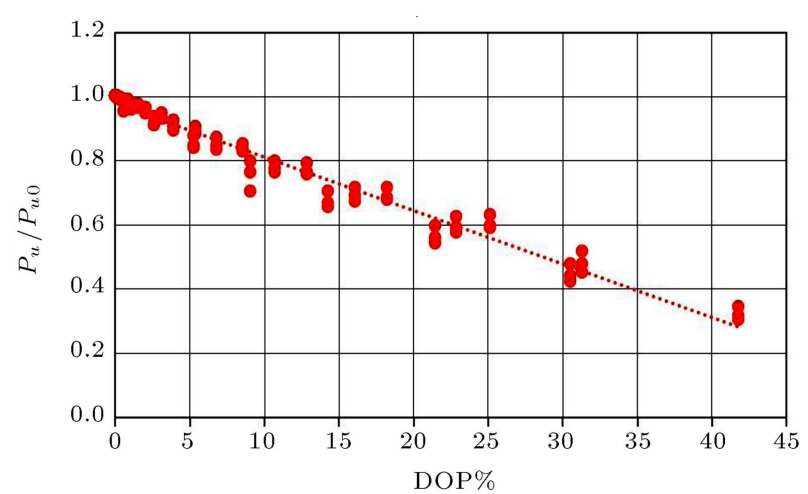

Figure 17. Ultimate strength versus DOP ratio for a steel web plate with pit corrosion under a compressive load.

to simulate a pitted corroded web beam with different DOPs with a uniform decreased thickness. It should be noted that the ultimate compressive strength based on the theoretical formulations (Eqs. (3) and (4)) for this plate web beam in an intact state give a close approximation to the FEA results.

The load carrying capacity of damaged pitted and uniformly corroded web beam plates is shown in Figures 17 and 18, respectively. Both sets of results are derived from the software. The thickness of the web plate decreases uniformly. The residual strength of the uniformly corroded and pitted specimens are

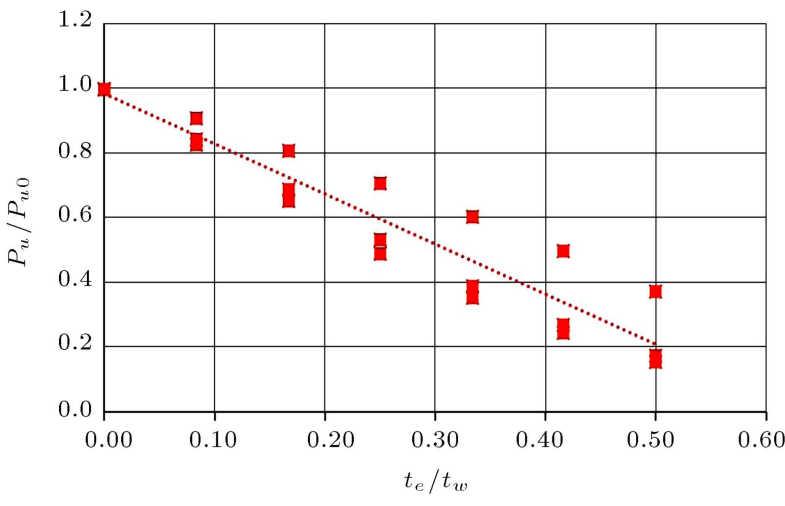

Figure 18. Ultimate strength versus web loss thickness for a steel web plate with uniform corrosion under a compressive load $\left(P_{u}\right.$ and $P_{u o}$ are the ultimate compressive strengths of the uniform thickness loss and intact plates, respectively).

examined and also shown in Figures 17 and 18. The ratio of the ultimate strength of the damaged specimen to the ultimate strength of the intact specimen in the cases of both pitting corrosion and uniform corrosion is developed using the formulae. It is evident that the ultimate compressive strength of the plate decreases, significantly, as the DOP level increases. The ultimate compressive strength reduction factor for a plate with pits and uniform corrosion can be expressed by regression analysis of the computed results as a function of the DOP and uniform thickness loss $\left(t_{e} / t_{w}\right)$ ratio, as follows:

$$
\frac{P_{u}}{P_{u o}}=-0.0167 \times(\mathrm{DOP})+0.9789, \quad R^{2}=0.9707,
$$

where $R$ is the coefficient of correlation:

$$
\begin{aligned}
& \frac{P_{u}}{P_{u o}}=-1.5466 \times\left(\frac{t_{e}}{t_{w}}\right)+0.9822, \text { for } t_{e} \succ 0, \\
& R^{2}=0.9022,
\end{aligned}
$$

where $P_{u}$ and $P_{u o}$ are the ultimate compressive strengths for the pitted and intact plates, respectively, and $t_{e}$ is the uniform web thickness loss.

Eqs. (3) and (4) summarise the computed results for the ultimate compressive strength as a function of DOP and uniform thickness loss $\left(t_{e} / t_{w}\right)$ ratio. As mentioned, the aim is to represent the pitted web plate with a plate that experiences a uniform decrease in the thickness across its surface. Eq. (5) presents the equivalent thickness loss as a function of the pitting corrosion intensity:

$$
\frac{t_{e}}{t_{w}}=1-\frac{t_{r}}{t_{w}}=0.0097 \times(\mathrm{DOP})+0.0263
$$$$
\text { for } \mathrm{DOP} \succ 0 \quad R^{2}=0.9966 \text {, }
$$

where $t_{e}, t_{w}$, and $t_{r}$ are the uniform web thickness loss, 
initial web thickness, and the remaining uniform web thickness, respectively.

In order to validate the proposed formulae, a set of simulations for steel web plate model with different geometries and levels of corrosion was simulated by ABAQUS. The model was set up based on the same modelling techniques discussed in Section 3 of this paper. The adopted element and mesh density, applied material properties, and boundary conditions are exactly the same as those of the validated $\mathrm{FE}$ model. A plate with the height of $500 \mathrm{~mm}$, breadth of $200 \mathrm{~mm}$, and original un-corroded thickness of $14 \mathrm{~mm}$ has been analysed. While $d_{p} / h_{p}$ ratio has been taken as 8 , the $d_{p}$ changes between $8 \mathrm{~mm}$ and $40 \mathrm{~mm}$ and, finally, DOP ranges from 0 to $35.89 \%$. It is evident from Figures 19, 20, and 21 that Eq. (3), (4), and (5) are valid for predicting the ultimate compressive strength of a steel web plate with pitting and uniform corrosion with different geometries and levels of corrosion.

\section{Concluding remarks}

This study investigates the effect of pitting corrosion on the strength of beam web plates subjected to compressive loading through a series of ABAQUS elastic-plastic large deflection finite element analyses with varying pit corrosion intensities. It is evident

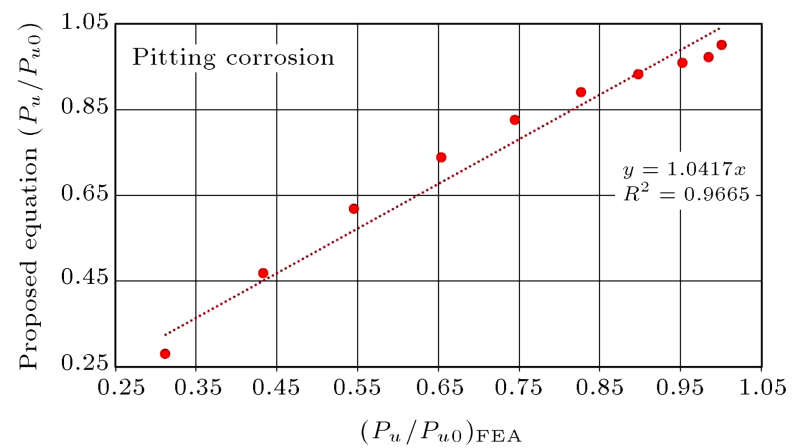

Figure 19. Accuracy of the ultimate strength predictions of Eq. (8) for a steel beam web plate with pits under a compressive load.

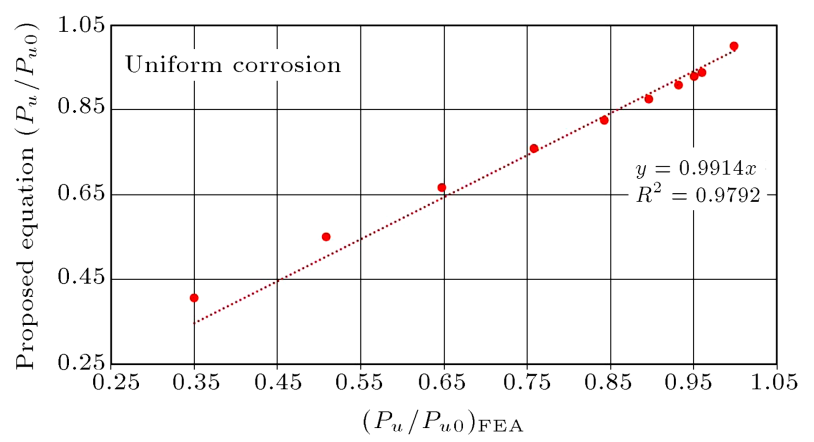

Figure 20. Accuracy of the ultimate strength predictions of Eq. (9) for a pitted steel beam web plate with uniform thickness loss under a compressive load.

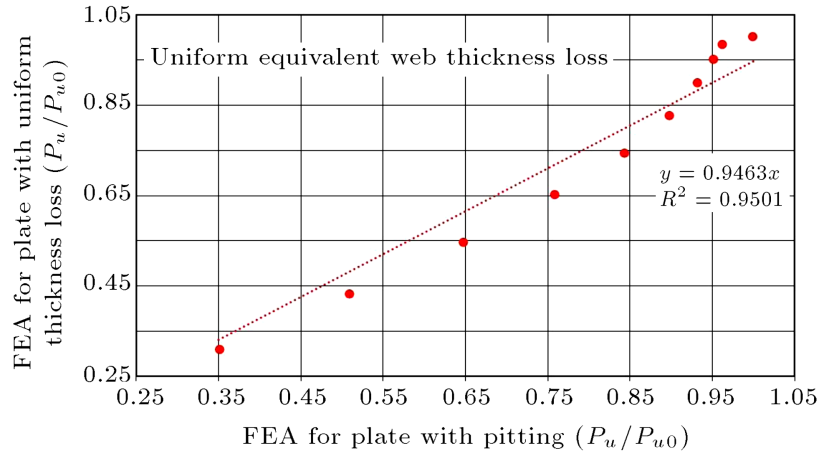

Figure 21. Accuracy of the ultimate strength predictions of Eqs. (9) and (10) for a pitted steel beam web plate with equivalent uniform thickness loss from Eq. (10) under a compressive load.

from the results that the ultimate strength of a plate element is significantly decreased by both pit corrosion and general or uniform corrosion. Although the ultimate strength of a plate with uniform corrosion can be calculated by excluding the thickness loss due to corrosion, predicting the ultimate strength of a pitted web plate beam is not a simple matter. This study, thus, focuses on investigating the ultimate strength behaviour of a beam web plate with pitting corrosion wastage. For practical purposes, the equivalent uniform thickness is shown to be an appropriate parameter for the evaluation of the beam behaviour of pitted web plates. The results and insights of this study should be useful in the damage tolerant design of steel beam structures with pit corrosion. The beam plate ultimate strength design formulae can also be used for the ultimate limit state based reliability or risk assessment of beam plated structures with web pit corrosion wastage.

\section{Acknowledgments}

The authors are pleased to acknowledge the support of Vali-e-Asr University of Rafsanjan.

\section{References}

1. Paik, J.K. and Thayamballi, A.K., Ultimate Limit State Design of Steel-Plated Structures, John Wiley \& Sons, Chichester, UK (2003).

2. Paik, J.K. and Melchers, R.E., Condition Assessment of Aged Structures, CRC Press, New York, USA (2008).

3. Nakai, T., Matsushita, H., Yamamoto, N. and Hironori, A. "Effect of pitting corrosion on local strength of hold frames of bulk carriers (1st report)", Marine Structures, 17, pp. 403-432 (2004).

4. Nakai, T., Matsushita, H. and Yamamoto, N. "Effect of pitting corrosion on strength of web plates subjected to patch loading", Thin-Walled Structures, 44, pp. 1019 (2006). 
5. Nakai, T., Matsushita, H. and Yamamoto, N. "Effect of pitting corrosion on the ultimate strength of steel plates subjected to in-plane compression and bending", Journal of Marine Science and Technology, 11(1), pp. 52-64 (2006).

6. Paik, J.K., Lee, J.M. and Ko, M.J. "Ultimate compressive strength of plate elements with pit corrosion wastage", Journal of Engineering Maritime Environment, 217(M4), pp. 185-200 (2003).

7. Paik, J.K., Lee, J.M. and Ko, M.J. "Ultimate shear strength of plate elements with pit corrosion wastage", Thin-Walled Structures, 42(8), pp. 1161-76 (2004).

8. Sharifi, Y. and Paik, J.K. "Ultimate strength reliability analysis of corroded steel-box girder bridges", ThinWalled Structures, 49(1), pp. 157-166 (2011).

9. Sharifi, Y. and Paik, J.K. "Environmental effects on ultimate strength reliability of corroded steel box girder bridges", Structural Longevity, 18(1), pp. 1-20 (2010).

10. Sharifi, Y. "Reliability of deteriorating steel boxgirder bridges under pitting corrosion", Advanced Steel Construction, 7(3), pp. 220-238 (2011).

11. Sharifi, Y. and Paik, J.K. "Maintenance and repair scheme for corroded stiffened steel box girder bridges based on ultimate strength reliability and risk assessments", Engineering Structures and Technologies, 6(3), pp. 43-53 (2014).

12. Melchers, R.E. "Development of new applied models for steel corrosion in marine applications including shipping", Ships and Offshore Structures, 3(2), pp. 135-144 (2008).

13. Melchers, R.E. and Paik, J.K. "Effect of flexure on rusting of ship's steel plating", Ships and Offshore Structures, 5(1), pp. 25-31 (2009).

14. Shehadeh, M. and Hassan, I. "Study of sacrificial cathodic protection on marine structures in sea and fresh water in relation to flow conditions", Ships and Offshore Structures, 8(1), pp. 102-110 (2013).

15. Sharifi, Y. and Tohidi, S. "Lateral-torsional buckling capacity assessment of web opening steel girders by artificial neural networks-elastic investigation", Frontiers of Structural and Civil Engineering, 8(2), pp. 167-177 (2014).

16. Sharifi, Y. and Tohidi, S. "Ultimate capacity assessment of web plate beams with pitting corrosion subjected to patch loading by artificial neural networks", Advanced Steel Construction, 10(3), pp. 325350 (2014).

17. Tohidi, S. and Sharifi, Y. "Restrained distortional buckling capacity of half through bridge girders", The IES Journal Part A: Civil \& Structural Engineering, 7(3), pp. 163-173 (2014).
18. Tohidi, S. and Sharifi, Y. "Inelastic lateral-torsional buckling capacity of corroded web opening steel beams using artificial neural networks", The IES Journal Part A: Civil \& Structural Engineering, 8(1), pp. 24-40 (2015).

19. Huang, Y., Zhang, Y., Liu, G. and Zhang, Q. "Ultimate strength assessment of hull structural plate with pitting corrosion damnification under biaxial compression", Ocean Engineering, 37(17-18), pp. 1503-1512 (2010).

20. ABAQUS user's manual, version 6.9. Pawtucket, RI: Hibbit, Karlsson \& Sorenson (2005).

21. Saad-Eldeen, S., Garbatov, Y. and Guedes Soares, C. "Compressive strength assessment of a moderately corroded box girder", Mar. Syst. Ocean Technol., 6, pp. 27-33 (2011).

22. Saad-Eldeen, S., Garbatov, Y. and Guedes Soares, C. "Experimental assessment of corroded steel boxgirders subjected to uniform bending", Ships and Offshore Structures, 8(6), pp. 653-662 (2013).

\section{Biographies}

Yasser Sharifi is an Associate Professor of Structural Engineering at Vali-e-Asr University of Rafsanjan in Iran. His areas of research are buckling and ultimate capacities of structures in association with limit states and risk-based approaches, and his other research areas have ranged from large scale (complete buildings) to small scale (material level) within the field of concrete structures.

Sajjad Tohidi received his MS degree in Structural Engineering from Vali-e-Asr University of Rafsanjan in Iran. His areas of research are buckling and ultimate capacities of steel structures and his other research areas are based on the application of intelligent methods in structural engineering.

Joem Kee Paik is a professor in the Department of Naval Architecture and Ocean Engineering at Pusan National University in Busan, Korea. He serves as president of the Korea Ship and Offshore Research Institute and also as director of the Lloyd's Register Foundation Research Centre of Excellence at the University. He is a fellow and council member of The Royal Institution of Naval Architects in UK, and a fellow and vice president of The Society of Naval Architects and Marine Engineers, USA. 